Andrews University

Digital Commons @ Andrews University

Faculty Publications

$1-1-2006$

\title{
A Retrospective, Descriptive Study of Shoulder Outcomes in Outpatient Physical Therapy
}

\author{
A. Lynn Millar \\ Andrews University, Imillar@andrews.edu \\ Philip A. Jasheway \\ Lakeland Rehabilitation Center \\ Wendy Eaton \\ Andrews University \\ Frances Christensen \\ Andrews University
}

Follow this and additional works at: https://digitalcommons.andrews.edu/pubs

Part of the Physical Therapy Commons

\section{Recommended Citation}

Millar, A. Lynn; Jasheway, Philip A.; Eaton, Wendy; and Christensen, Frances, "A Retrospective, Descriptive Study of Shoulder Outcomes in Outpatient Physical Therapy" (2006). Faculty Publications. 1871. https://digitalcommons.andrews.edu/pubs/1871

This Article is brought to you for free and open access by Digital Commons @ Andrews University. It has been accepted for inclusion in Faculty Publications by an authorized administrator of Digital Commons @ Andrews University. For more information, please contact repository@andrews.edu. 


\title{
A Retrospective, Descriptive Study of Shoulder Outcomes in Outpatient Physical Therapy
}

\author{
A. Lynn Millar, PT, PhD, FACSM ${ }^{1}$ \\ Philip A. Jasheway, PT, OCS, ATC, CSCS ${ }^{2}$ \\ Wendy Eaton, MSPT ${ }^{3}$ \\ Frances Christensen, MSPT ${ }^{3}$
}

Study Design: A retrospective, descriptive study of clients with shoulder dysfunction referred to physical therapy.

Objectives: To (1) describe the clinical and functional outcomes of clients with shoulder dysfunction following outpatient physical therapy, and (2) to compare the outcomes by type of shoulder dysfunction.

Background: Although individuals with shoulder dysfunction are commonly referred to physical therapy, few large descriptive studies regarding outcomes following physical therapy are available. Methods and Measures: Data for 878 clients (468 female, 410 male) were retrieved and analyzed. This database was developed between 1997 and 2000 and included 4 outpatient facilities from 1 healthcare system in the southwest corner of Michigan. Clients were classified by type of shoulder dysfunction, and standardized tests were performed upon admittance and discharge to physical therapy. Descriptive and inferential statistics were calculated for all data.

Results: Of all clients, $55.1 \%$ had shoulder impingement, while $18.3 \%$ had postoperative repair $8.9 \%$ had a frozen shoulder, $7.6 \%$ had a rotator cuff tear, 3.0\% had shoulder instability, $2.1 \%$ were post fracture, and the remaining $4.9 \%$ had miscellaneous diagnoses. The average $( \pm \mathrm{SD})$ age of the patients was $53.6 \pm 16.4$ years, with an average $( \pm$ SD) number of treatment sessions of 13.7 \pm 11.0 . All groups showed significant changes following physical therapy intervention.

Conclusions: Clients with diverse types of shoulder dysfunction demonstrated improvement in both clinical and functional measures at the conclusion of physical therapy, although it is not possible to determine whether these changes were due to the interventions or due to time. The type of shoulder dysfunction appears to affect the prognosis, thus expected outcomes should be based upon initial diagnosis and specific measures. J Orthop Sports Phys Ther 2006;36(6):403414. doi:10.2519/jospt.2006.2101

Key Words: adhesive capsulitis, rotator cuff, shoulder impingement, shoulder instability

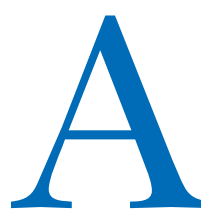

lthough clients with shoulder dysfunction are commonly seen in physical therapy, few large descriptive studies on this population have been published. ${ }^{21,25,35}$ The studies that do exist often classify patients under the broad range of "shoulder pain" or chronicity of shoulder pain. ${ }^{15,18,34}$ Diagnoses can include adhesive capsulitis, supraspinatus tendonitis, fracture,

\footnotetext{
Professor of Physical Therapy, Andrews University, Berrien Springs, MI.

2 Sports Therapy Staff, Lakeland Rehabilitation Center, St Joseph, MI.

3 Graduate student (at time of study), Department of Physical Therapy, Andrews University, Berrien Springs, MI.

The protocol for this study was approved by The Institutional Review Board of Andrews University. Address correspondence to A. Lynn Millar, Department of Physical Therapy, Andrews University, Berrien Springs, MI 49104.E-mail: Imillar@andrews.edu
}

or postoperative repairs, which can limit specific application to practice when studied together. ${ }^{21,34,35}$ This suggests the need for a comprehensive, useful classification system. In addition, studies often focus on interventions for 1 or 2 subcategories of shoulder diagnosis, some with only a limited number of dependent variables. ${ }^{3,6}$, $7,8,22,29$ This may limit the application of the study. Several studies have noted the recalcitrant nature of shoulder dysfunction. Chard et $\mathrm{al}^{10}$ found an average duration of symptoms ranging from 19 to 50 months, while van der Windt and colleagues $^{35}$ reported that almost half of those with shoulder complaints had symptoms for 1 month or more. Thus, a recent Cochrane Review highlighted the need for more studies on combined physical therapy interventions, as well as a variety of shoulder conditions. $^{21}$

The primary purpose of this retrospective study was to describe the clinical outcomes of all clients with shoulder dysfunction referred to outpatient physical therapy in a multicenter health system over a 4-year period. A second intention was to compare outcomes between individuals with different classifications of shoulder dysfunction. Considering that descriptive stud- 
TABLE 1. Shoulder classification guide. An example of its use would be a bursitis after a fall, with a capsular pattern, which would be classified as S1CT.

\begin{tabular}{l} 
S1. Impingement, including bursitis and rotator cuff tendonitis \\
\hline Restriction \\
N, noncapsular restriction \\
C, capsular restriction (external rotation more limited than \\
internal rotation at $90^{\circ}$ abduction) \\
Type \\
T, traumatic \\
I, insidious \\
\hline S2. Rotator cuff tear (any size lesion as confirmed by MRI) \\
\hline Type \\
T, traumatic \\
I, insidious \\
\hline S3. Frozen shoulder (adhesive capsulitis, periarthritis, \\
periarticular adhesions, stiff shoulder, etc) \\
\hline Type \\
T, traumatic \\
I, insidious \\
\hline S4. Postoperative \\
\hline A, acromioplasty \\
B, rotator cuff repair \\
C, open reduction internal fixation-fracture \\
D, capsular shift \\
\hline S5. Instability \\
\hline U, unidirectional \\
M, multidirectional \\
\hline S6. Fracture \\
\hline A, humerus \\
B, clavicle \\
C, scapula \\
\hline S7. Miscellaneous \\
\hline
\end{tabular}

ies are considered one important level of evidence, this study may provide the clinician with some idea of the scope of impairments and clinical presentation for different shoulder dysfunctions. In addition, although changes over time that are identified in a descriptive study cannot be directly attributed to one intervention, or to the interventions versus time, they may give the therapist some idea of the typical clinical response.

\section{METHODS}

\section{Clients}

Client data were obtained for this retrospective study from the Lakeland Regional Healthcare System database. This healthcare system includes 4 outpatient clinics in the southwest corner of Michigan and maintains a multicenter patient database. Records for all clients who received physical therapy for a shoulder dysfunction during a 4-year period (1997-2000) were included in this database. Prior to inception of the shoulder client database, protocols for clinical tests were standardized with all therapists for consistency. Following a systemwide training session, each therapist practiced the clinical tests, with the lead therapist providing feedback. Therapists joining the healthcare system after inception of the database were trained prior to their data being included in the database. Approximately 45 therapists contributed to the client database. It should be emphasized that this system and database were initiated for quality control and not as a research tool. The protocol for the retrospective study was approved by the Institutional Review Board of Andrews University and The Internal Review Board for the Lakeland Regional Healthcare System.

\section{Measurements}

Demographic Information The clients' age at the time of the initial examination, gender, and comorbidities were identified. Comorbidity was identified as no comorbid disease, mild systemic comorbid disease, systemic disease that limits activity, and incapacitating comorbid disease, as based on the American Society of Anesthesiologists (ASA) grade. ${ }^{30}$ The therapist assigned this rating based on a combination of written intake information and the history portion of the initial evaluation. Shoulder dysfunction was classified into 7 categories: impingement (IMP), rotator cuff tear (RCT), postoperative (PO), instability (INS), fracture (FX), frozen shoulder (FZ), or miscellaneous (MISC). Within each category were subcategories, such as type of restriction, initial incident (traumatic or insidious), type of surgery, instability, or fracture. The classification scheme is shown in Table 1.

Classification was determined by the physical therapist, based on assessment results using accepted criteria, history, and information provided by the referring physician. Impingement was determined based on a positive Neer's impingement test. ${ }^{31}$ The pattern of restriction for impingement and frozen shoulder was identified using Cyriax's capsular pattern, based on range-of-motion (ROM) measures. ${ }^{13}$ The rotator cuff tear classification included those whose tear was confirmed by MRI, but did not have surgical repair of the tear. The postoperative and fracture classifications were determined by the referring physician. Unidirectional instability was identified by a positive apprehension test, distinguished from multidirectional instability, which was determined by a positive Sulcus sign or a combination of positive anterior and posterior apprehension tests. ${ }^{16}$

Functional Measures Two functional measures were assessed for all shoulder patients: work status and functional status. Work status was ranked on a 4-point scale, based on client report: (1) patient off work and/or needs help with most home duties because of problem; (2) patient on restricted duties and/or 
needs help with some home duties because of problem; (3) patient able to do work and/or home duties but it causes extra pain; (4) patient currently working full duties and/or able to do all regular home duties.

Functional status was assessed using an index which had been developed and validated for this clinic, as there were limited published scales when the client database was initiated. ${ }^{14}$ The scale was significantly correlated to impairments in ROM, with changes in the scale following intervention having correlations between 0.52 to 0.99 to changes in each of the ROM measures. The lowest correlations were to those ranges that did not exhibit significant losses prior to therapy, nor changes with therapy, such as shoulder internal rotation. The questionnaire includes components on reaching overhead, sleeping, dressing, selfcare and grooming, and lifting and carrying. For each area, the client checked the statement corresponding to function related to that area. Each area ranged from no restrictions for that function to complete inability to perform the function. Pain assessment was incorporated into each of the components, allowing the distinction between pain as the restrictor of an activity, or the shoulder function itself. The initial research for this scale, and others, has shown that inclusion of pain within each of the areas improves the validity of the questionnaire. ${ }^{14,24}$ The higher the score, the lower the functional level, while the lowest scores represent complete independence with all activities (0-25). Thus, each point improvement represented a decrease of pain with an activity and improvement of function related to that activity. However, evidence of responsiveness and reliability has not been evaluated for this tool, which is a limitation to its use in this study.

Clinical Tests The established assessment schedule was initial, discharge, and every fifth visit or 2 weeks, whichever came first. Active shoulder ROM was recorded for flexion and abduction, with the arm positioned as described by Clarkson and Gilewich, ${ }^{11}$ while the subject was standing. Passive range of motion (PROM) was measured for external rotation with the shoulder at $90^{\circ}$ of abduction and in a neutral (adducted) position. A long-arm goniometer was used for all measures, with values recorded to the nearest degree. Internal rotation PROM was assessed using the methods described by Clarkson and Gilewich. ${ }^{11}$ Boone et $\mathrm{al}^{5}$ showed goniometric measures to be reliable, with an intertester reliability of 0.97 and intratester reliability of 0.96 , with associated variability (SE) of $3.8^{\circ}$ to $4.0^{\circ}$ for the shoulder ranges. Riddle et $\mathrm{al}^{32}$ showed significantly lower reliability values for shoulder extension, thus this measure was not included in our evaluation. In addition, combined shoulder movement was assessed actively using a protocol developed in this system. The movement combined shoulder internal rotation, extension, and adduction, with the subjects being asked to place their hand behind their back and touch their spine with their hand, thumb up. They were instructed to touch as high as possible. Warner et $\mathrm{al}^{38}$ used this method, but used the vertebral level to identify the measure, following the technique identified by the American Academy of Orthopaedic Surgeons (AAOS). ${ }^{1}$ To improve quantification for our system, the movement was measured in centimeters, with distance from the occiput to the thumb recorded. An unpublished pilot study comparing individual height to this measure showed no significant correlation $(r=0.42)$, though the most important use of the value was not as a normative value but as an individual measure for response to intervention. Values were not recorded until the client was able to reach the spine actively. Intertester reliability of the technique was established using 2 therapists who tested the same 10 individuals. Intraclass correlation coefficient for the pilot reliability study was 0.93 for single measures. In the clinic, we find this test a useful indicator of specific functional abilities, such as the ability to tuck in a shirt, do up a bra, etc.

Shoulder strength for external rotation was assessed using manual muscle testing (MMT) following the protocol of Kendall et al. ${ }^{26}$ MMT is commonly used in the clinic to provide a rapid screen of gross muscle strength and potential myotome weakness. Wadsworth et $\mathrm{al}^{36}$ found test-retest reliability for shoulder strength measures of 0.98 , while Hayes et $\mathrm{al}^{25}$ reported intrarater values ranging from 0.79 to 1.00 , with lower interrater values between 0.55 to 0.73 . Manual muscle grades with a minus or plus were entered as such and converted down or up, respectively, by thirds for statistical analysis. For example a score of 4- was recorded as 3.7, while a score of 3+ was recorded as a 3.3. This is reflective of the true continuum of MMT grades. The use of MMT scores represents a limitation to this study, as this form of assessment lacks responsiveness to small changes in strength. However, for clinical purposes it is a quick test and allows gross assessment of functional strength. The large number of subjects in this study provided the statistical power for determining differences in this limited scale measurement.

Intervention The interventions for each client were based upon their individual impairments and function. These interventions were consistent with the Guide to Physical Therapist Practice ${ }^{2}$ and based upon current practice at that time. ${ }^{6,19}$ Thus, therapeutic interventions potentially included exercise, manual therapy, ultrasound, phonophoresis, electrical stimulation, iontophoresis, ice, heat, and client education. Therapists recorded the primary treatment emphasis for the first treatment session; however, it should be emphasized that no session used exclusively 1 type of intervention, as is consistent with typical physical therapy practice. While we cannot state that all therapists used evidence-based practice (for that pe- 
TABLE 2. Descriptive data for age in years and gender distribution by shoulder category.

\begin{tabular}{|c|c|c|c|}
\hline \multirow[b]{2}{*}{ Shoulder Category } & \multirow{2}{*}{$\frac{\text { Age }}{\text { Mean } \pm \text { SD }}$} & \multicolumn{2}{|c|}{ Gender } \\
\hline & & Females (n) & Males (n) \\
\hline Impingement $(\mathrm{n}=469)$ & $52.1 \pm 15.4$ & 268 & 201 \\
\hline Rotator cuff tear $(n=63$ ) & $61.3 \pm 13.3$ & 26 & 37 \\
\hline Frozen shoulder $(n=75)$ & $58.6 \pm 13.7$ & 49 & 26 \\
\hline Postoperative $(\mathrm{n}=156)$ & $51.9 \pm 14.7$ & 56 & 100 \\
\hline Instability $(n=26)$ & $30.6^{*} \pm 20.3$ & 15 & 11 \\
\hline Fracture $(n=18)$ & $58.4 \pm 17.6$ & 12 & 6 \\
\hline Miscellaneous $(n=41)$ & $44.1 \pm 17.8$ & 23 & 18 \\
\hline Total $(\mathrm{n}=848)$ & $52.4 \pm 16.2$ & $449^{+}$ & 399 \\
\hline
\end{tabular}

riod), regular inservices were held, identifying the most current intervention evidence at that time, with an emphasis on putting such information into practice.

\section{Data Analysis}

The relevant data were exported into Excel and imported into SPSS, version 12.0. Prior to performing statistical analyses, the data were examined for outliers. Only data falling out of the normal, possible range were eliminated. For example, the functional score could range from 0 to 25 ; therefore, any score above 25 was due to input error. When the records were available, these were corrected. Otherwise, the measure was discarded for that individual. Thus, the available number of patient cases varies for each variable.

Demographic data were analyzed using descriptive statistics (means and standard deviations are presented for all continuous variables; frequencies and percentages are presented for scale or nominal data). A 2-way ANOVA was used to assess the differences for ages among shoulder groups and gender. Chi-square analyses were used to assess the association between shoulder group and gender, as well as comorbidity status. Chi-square analyses for independence were also used for shoulder instability, gender, and work status by shoulder classification.

Correlations between admission impairment measures, age, and function were calculated using a Pearson product moment correlation to determine if covariate analyses were required. One-way ANOVAs were used to compare differences among shoulder classification groups before intervention for general descriptive purposes. A mixed-model ANOVA with repeated measures for time was then used to assess differences between groups over time. A partial eta-squared (effect size) was calculated for all ANOVAs. Tukey honestly significant difference (HSD) post hoc analyses were used to identify specific group differences. Initial analyses included all 7 shoulder categories, with subcategories, while subsequent analy- ses used each of the categories without subcategories, due to findings of no difference among the subcategories within all but 1 of the categories. Although MMT is truly ordinal data, with the use of minus or plus categories the measure takes on some of the mathematical properties of continuous data. ANOVAs are considered "robust" and may be used when normally ordinal data has some of the properties of continuous data. Statistical analyses were considered significant if equal or below the .05 level of probability.

\section{RESULTS}

Demographic Information The total number of patients was 878 (468 female, 410 male). The average $( \pm \mathrm{SD})$ age of the patients was $52.4 \pm 16.2$ years. Average ages for the groups ranged from a low of 30.6 years for the INS group, to a high of 61.3 years for the RCT group. The distribution for age and gender for each group is presented in Table 2. A 2-way ANOVA using group and gender revealed a significant difference $(\mathrm{F}=17.52 ; d f=6,834 ; P<.001)$ between the ages of the groups and between the ages by gender $(\mathrm{F}=8.699 ; d f=1,834 ; P=.003)$, but no interaction between gender and group. The average $( \pm \mathrm{SD})$ age of the female clients was $53.6 \pm 16.4$, while the age for the males averaged $51.1 \pm 15.8$ years. A chi-square analysis showed a significant association between gender and shoulder group $\left(\chi^{2}=43.693\right.$, $d f$ $=12, P<.001)$. As can be seen in Table 1 , there are almost twice as many females as males in the FZ and FX groups, while half as many are in the PO group.

The average number of visits for each patient was $13.7 \pm 11.0$. A 1-way ANOVA revealed a significant difference $(\mathrm{F}=33.82 ; d f=6,846 ; P<.001)$ between the number of visits for each group. A Tukey post hoc comparison showed INS, IMP, and MISC groups having the least number of treatment sessions (mean, 10.5 visits) and the PO groups having the most (mean, 25.6 visits). Descriptive data for all groups for the number of visits is presented in Table 3 .

A frequency distribution of the number of comorbidities present in the patient population 
TABLE 3. Descriptive data for number of physical therapy visits per patient for each shoulder category.

\begin{tabular}{llcr}
\hline Groups & Mean \pm SD & Minimum-Maximum & Median \\
\hline Impingement $(n=470)$ & $10.7 \pm 7.2$ & $1-53$ & 9 \\
Rotator cuff tear $(n=65)$ & $14.8 \pm 10.8^{+}$ & $2-49$ & 13 \\
Frozen shoulder $(n=76)$ & $14.3 \pm 8.9^{+}$ & $1-48$ & 12 \\
Postoperative $(n=156)$ & $23.5 \pm 15.9^{*}$ & $1-82$ & 8 \\
Instability $(n=26)$ & $10.5 \pm 8.2$ & $1-38$ & 12 \\
Fracture $(n=18)$ & $13.3 \pm 8.1$ & $4-33$ & 8 \\
Miscellaneous $(n=42)$ & $10.5 \pm 8.9$ & $1-34$ & 11 \\
Total $(n=853)$ & $13.7 \pm 11.0$ & $1-82$ & \\
\hline
\end{tabular}

* Significantly different from all other categories $(P<.05)$.

${ }^{+}$Significantly different from impingement category $(P<.05)$.

TABLE 4. Cross-tabulation of shoulder category by work status at admission.

\begin{tabular}{|c|c|c|c|c|c|c|c|c|}
\hline & Impingement & $\begin{array}{c}\text { Rotator } \\
\text { Cuff } \\
\text { Tear }\end{array}$ & $\begin{array}{l}\text { Frozen } \\
\text { Shoulder }\end{array}$ & Postoperative & Instability & Fracture & Miscellaneous & Tota \\
\hline \multicolumn{9}{|l|}{ Off work $(n=180)$} \\
\hline Work status $(\%)$ & 24.4 & 12.2 & 5.0 & 47.8 & 1.7 & 3.3 & 5.6 & \\
\hline Shoulder category (\%) & 9.4 & 34.4 & 11.8 & 55.1 & 11.5 & 33.3 & 23.8 & 21.1 \\
\hline \multicolumn{9}{|l|}{ Restricted duties $(\mathrm{n}=201)$} \\
\hline Work status (\%) & 49.3 & 9.5 & 10.0 & 19.9 & 2.5 & 3.5 & 5.5 & \\
\hline Shoulder category (\%) & 21.1 & 29.7 & 26.3 & 25.6 & 19.2 & 38.9 & 26.2 & 23.6 \\
\hline \multicolumn{9}{|l|}{ Work with pain $(\mathrm{n}=382)$} \\
\hline Work status (\%) & 69.9 & 5.5 & 10.2 & 7.1 & 2.9 & 1.0 & 3.4 & \\
\hline Shoulder category (\%) & 56.8 & 32.8 & 51.3 & 17.3 & 42.3 & 22.2 & 31.0 & 44.8 \\
\hline \multicolumn{9}{|l|}{ Full work $(\mathrm{n}=89)$} \\
\hline Work status (\%) & 67.4 & 2.2 & 9.0 & 3.4 & 7.9 & 1.1 & 9.0 & \\
\hline Shoulder category $(\%)$ & 12.8 & 3.1 & 10.5 & 1.9 & 26.9 & 5.6 & 19.0 & 10.4 \\
\hline Total $(n=852)$ & & & & & & & & \\
\hline $\begin{array}{l}\text { Within admission work } \\
\text { status (\%) }\end{array}$ & 55.2 & 7.5 & 8.9 & 18.3 & 3.1 & 2.1 & 4.9 & \\
\hline
\end{tabular}

showed that $61.2 \%(\mathrm{n}=537)$ of patients had no other disease. Mild systemic disease was present along with the shoulder problem in $33.4 \%(n=294)$ of the patients, while $4.8 \%(\mathrm{n}=42)$ had systemic disease that limited activity, and $0.6 \%(n=5)$ of the patients had incapacitating comorbidities. There was a significant association between comorbidity status and shoulder group $\left(\chi^{2}=41.983, d f=18, P<.001\right)$, with the RCT group having a higher proportion in the mild systemic disease category.

Functional Measures For admission work status (Table 4), the largest category were those able to do work and home duties with pain $(44.8 \%)$, followed by $23.6 \%$ in restricted duties, $21.1 \%$ off work, and $10.4 \%$ doing full work duties. There was a significant difference among groups for work status at admission $\left(\chi^{2}=\right.$ 206.797, $d f=18, P<.001)$. As might be anticipated, the highest percentage in the off work or on restricted duties categories were those within the PO $(81.1 \%)$, FX $(72.2 \%)$, or RCT $(64.1 \%)$ groups. There was a significant change in distribution within work status by discharge (Table 5), though still a significant association between shoulder classification and work status $\left(\chi^{2}=38.467, d f=18, P=.003\right)$. The total within the full-work status increased to $45 \%$, with a concomitant decrease within the able to do workwith-pain $(35.8 \%)$, restricted-work $(12.1 \%)$, and offwork $(6.9 \%)$ categories. The largest groups within the able-to-do-work-with-pain and full-work categories were the INS $(88.4 \%)$, the FZ $(86.6 \%)$, and IMP $(85 \%)$ groups. The RCT group showed the least amount of change with only $26.6 \%$ in the full-work category.

While age was found to be significantly correlated to most of the impairment and functional measures (ranging from $r=0.098$ to $r=-0.214, P<.05$ ), covariate analyses did not result in any difference for the ANOVAs. A 1-way ANOVA revealed a significant difference among groups for initial function $(\mathrm{F}=$ 47.468; $d f=6,822 ; P<.001)$. There was a significant improvement between admission and discharge functional scores $(\mathrm{F}=282.05 ; d f=1,759 ; P<.001)$, as well as a difference between the responses of the groups $(\mathrm{F}=25.669 ; d f=6,759 ; P<.001)$. There was an average improvement of 5 points (25-point scale), with the magnitude of the changes equaling 0.271 
TABLE 5. Cross tabulation of shoulder category by work status at discharge.

\begin{tabular}{|c|c|c|c|c|c|c|c|c|}
\hline & Impingement & $\begin{array}{c}\text { Rotator } \\
\text { Cuff } \\
\text { Tear }\end{array}$ & $\begin{array}{l}\text { Frozen } \\
\text { Shoulder }\end{array}$ & Postoperative & Instability & Fracture & Miscellaneous & Total \\
\hline \multicolumn{9}{|l|}{ Off work $(n=58)$} \\
\hline Work status (\%) & 46.4 & 12.1 & 5.2 & 22.4 & 1.7 & 3.4 & 8.6 & \\
\hline Shoulder category (\%) & 5.9 & 10.9 & 4.0 & 8.6 & 3.8 & 11.1 & 11.1 & 6.9 \\
\hline \multicolumn{9}{|l|}{ Restricted duties $(\mathrm{n}=101)$} \\
\hline Work status $(\%)$ & 40.6 & 11.9 & 6.9 & 28.7 & 2.0 & 3.0 & 6.9 & \\
\hline Shoulder category (\%) & 8.9 & 18.8 & 9.3 & 19.2 & 7.7 & 16.7 & 16.7 & 12.1 \\
\hline \multicolumn{9}{|l|}{ Work with pain $(n=299)$} \\
\hline Work status (\%) & 60.5 & 9.4 & 8.4 & 14.4 & 2.3 & 0.7 & 4.3 & \\
\hline Shoulder category (\%) & 39.3 & 43.8 & 33.3 & 28.5 & 26.9 & 11.1 & 31.0 & 35.8 \\
\hline \multicolumn{9}{|l|}{ Full work $(\mathrm{n}=378)$} \\
\hline Work status (\%) & 55.8 & 4.5 & 10.6 & 17.5 & 4.2 & 2.9 & 4.5 & \\
\hline Shoulder category (\%) & 45.9 & 26.6 & 53.3 & 43.7 & 61.5 & 61.5 & 40.5 & 45.2 \\
\hline Total $(n=836)$ & & & & & & & & \\
\hline $\begin{array}{l}\text { Within admission work sta- } \\
\text { tus }(\%)\end{array}$ & 55.0 & 7.7 & 9.0 & 18.1 & 3.1 & 2.2 & 5.0 & \\
\hline
\end{tabular}

and 0.169 for changes over time for all individuals and for changes over time by category, respectively. Interpretation of partial eta-squared has not been standardized, but Cohen ${ }^{12}$ suggests the following interpretation for eta-squared: .01, small effect; .06, moderate effect; and .14, large effect. Post hoc tests revealed that the INS, IMP, and MISC groups were significantly different from the FX, RCT, and PO groups. These changes are illustrated graphically in Figure 1.

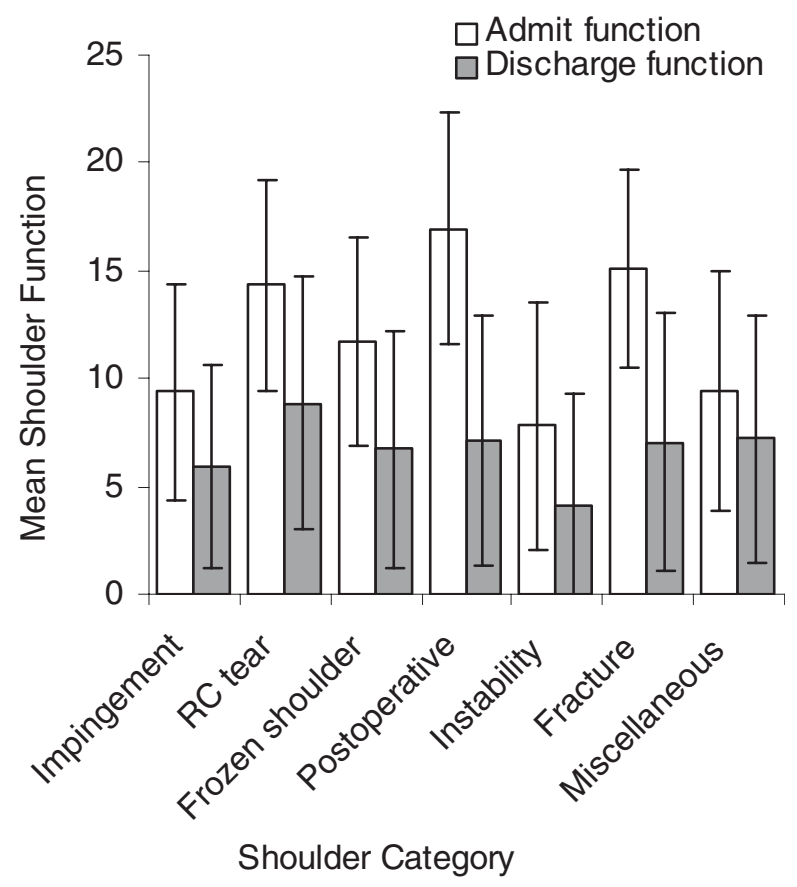

FIGURE 1. Comparison of average admission versus discharge function scores by shoulder classification categories $(0$, full function without pain; 25, very limited function with pain affecting all activities; bars represent mean $\pm \mathrm{SD}$ ).
Clinical Tests One-way ANOVAs revealed significant differences among groups for shoulder flexion ROM at time of admission $(\mathrm{F}=34.156 ; d f=6,840$; $P<.001)$, shoulder abduction $(\mathrm{F}=42.68 ; d f=6,836$; $P<.001)$, shoulder active internal rotation $(\mathrm{F}=3.358$; $d f=6,833 ; P=.003)$, passive internal rotation $(\mathrm{F}=$ $13.615 ; d f=6,802 ; P<.001)$, and passive external rotation at $90^{\circ}(\mathrm{F}=19.349 ; d f=6,773 ; P<.001)$. Post hoc tests identified numerous significant differences between groups; in general, shoulder ROM was better for the INS, IMP, and MISC groups, while the FZ, RCT, FX, and PO groups had less ROM at admission.

All groups showed a significant improvement over time and a significant difference between the responses of the groups was also noted for all measures except for shoulder internal rotation ROM. The average amount of change for each motion, along with the ANOVA values, are presented in Table 6, and the differences among groups over time are illustrated in Figures 2 through 7. Post hoc tests showed significant differences among groups for change over time for each of the impairment measures. Figure 8 presents a summary of the specific between-group differences.

Strength measures for shoulder external rotation are presented in Table 7 . There was a significant difference in change for the INS and IMP groups as compared to the RCT and FX groups. The IMP group was also significantly different from the $\mathrm{PO}$ group. The statistical validity of the differences with the FX group is likely low, as the number of patients in this group was only 8; strength was not tested on the majority of patients with FX upon admission, thus pre-post comparisons were limited.

Interventions The most common emphasis for the first intervention was exercise for mobility at $23 \%$, followed by strength exercise $(16 \%)$, manual 
TABLE 6. ANOVA Table for shoulder range of motion measures.

\begin{tabular}{|c|c|c|c|c|}
\hline & $\begin{array}{c}\text { Change } \\
\text { (mean } \pm \\
\text { SD)* }\end{array}$ & $\mathbf{F}$ & $P$ & $\begin{array}{c}\text { Partial } \\
\text { Eta- } \\
\text { Squared }\end{array}$ \\
\hline Flexion $\left(^{\circ}\right)$ & $23.8 \pm 33.4$ & & & \\
\hline Over time & & 252.549 & $<.001$ & .246 \\
\hline Groups $\times$ time & & 8.906 & $<.001$ & .065 \\
\hline Abduction $\left(^{\circ}\right)$ & $25.0 \pm 37.4$ & & & \\
\hline Over time & & 184.44 & $<.001$ & .194 \\
\hline Groups $\times$ time & & 6.432 & $<.001$ & .048 \\
\hline Active IR (cm) & $4.1 \pm 13.4$ & & & \\
\hline Over time & & 29.68 & $<.001$ & .037 \\
\hline Groups $\times$ time & & 4.858 & $<.001$ & .037 \\
\hline Passive IR $\left(^{\circ}\right)$ & $7.2 \pm 22.3$ & & & \\
\hline Over time & & 33.629 & $<.001$ & .043 \\
\hline Groups $\times$ time & & 0.653 & .687 & \\
\hline $\begin{array}{l}\text { Passive ER in } 90^{\circ} \\
\text { abduction }\left(^{\circ}\right)\end{array}$ & $9.7 \pm 23.4$ & & & \\
\hline Over time & & 74.11 & $<.001$ & .097 \\
\hline Groups $\times$ time & & 4.448 & $<.001$ & .037 \\
\hline $\begin{array}{l}\text { Passive ER in adduc- } \\
\text { tion }\left(^{\circ}\right)\end{array}$ & $9.8 \pm 18.8$ & & & \\
\hline Over time & & 111.706 & $<.001$ & .153 \\
\hline Groups $\times$ time & & 13.587 & $<.001$ & .117 \\
\hline
\end{tabular}

therapy/PROM (12\%), phonophoresis (12\%), and iontophoresis $(11 \%)$. There was a significant association between the first intervention emphasis and shoulder classification $\left(\chi^{2}=461.998, \quad d f=72\right.$, $P<.0005)$ consistent with the diagnosis and impairments.

\section{DISCUSSION}

To our knowledge this is the first study that has looked at outcomes following physical therapy for a wide variety of shoulder dysfunctions by shoulder dysfunction classification. We believe that our data confirm some clinical observations regarding rehabilitation outcomes of clients with shoulder dysfunction, while giving more specific information that is not available in the literature. We believe the large number of clients allows greater generalization than previous descriptive studies. ${ }^{27,35,38}$ The slightly higher distribution of females than males (53\% versus $47 \%$, respectively) is similar to that noted by van der Windt et $\mathrm{al}^{35}$ ( $56 \%$ and $44 \%$, respectively). Although the low numbers within some of the shoulder classifications limits the generalizations that we can make regarding those subgroups, the difference in distribution of genders within the groups does need to be addressed. With twice as many women as men presenting with frozen shoulder and postfracture, this is a potential area for follow-up. Kozin ${ }^{27}$ notes that adhesive capsulitis is more prevalent in individuals over the age of 50 and in women, which is corroborated by our findings. The higher incidence of osteopenia and osteoporosis in females could make them more sus-

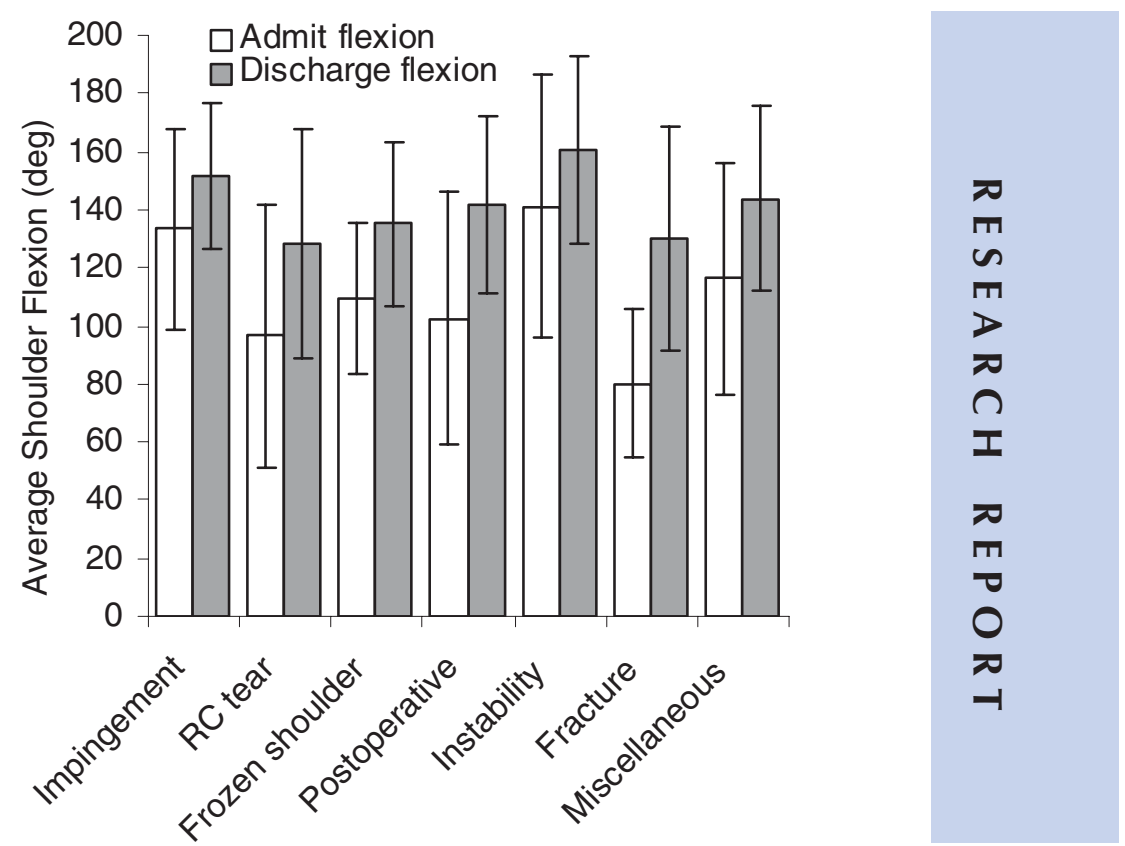

Shoulder Category

FIGURE 2. Admission and discharge shoulder flexion range of motion by shoulder classification categories (bars represent mean \pm SD).

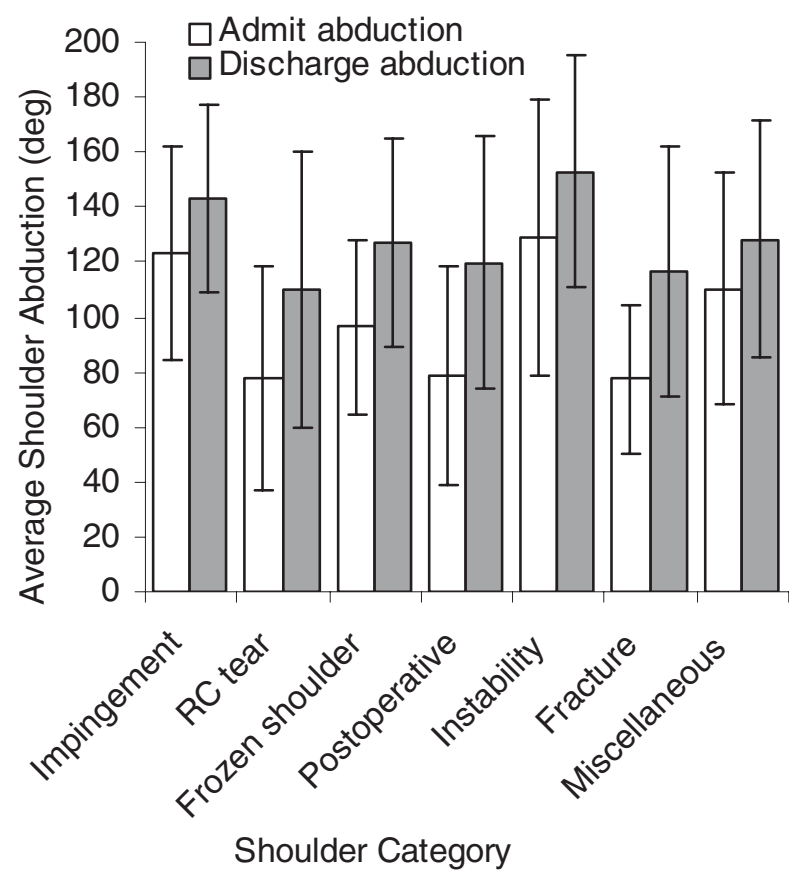

FIGURE 3. Admission and discharge shoulder abduction range of motion by shoulder classification categories (bars represent mean \pm SD).

ceptible to fractures. We did not have the ability to review charts to determine whether those individuals with fractures also had osteopenia. However, this potential relationship may explain our findings. The distribution of gender for postoperative repairs is also of interest. We can only hypothesize that perhaps more men are involved in activities that might subject 


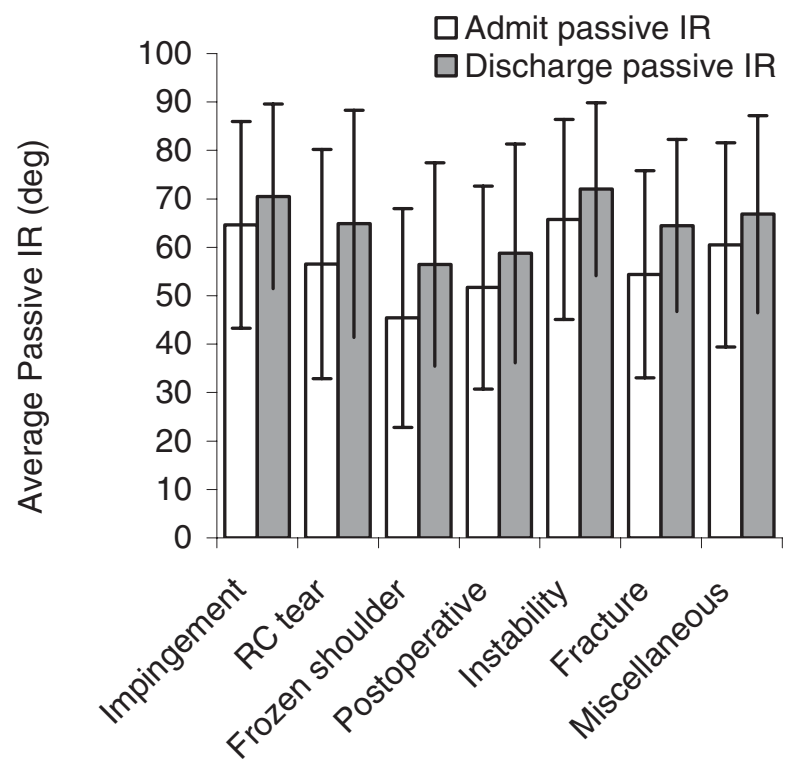

Shoulder Category

FIGURE 4. Admission and discharge shoulder passive internal rotation (IR) range of motion by shoulder classification categories (bars represent mean $\pm \mathrm{SD}$ ).

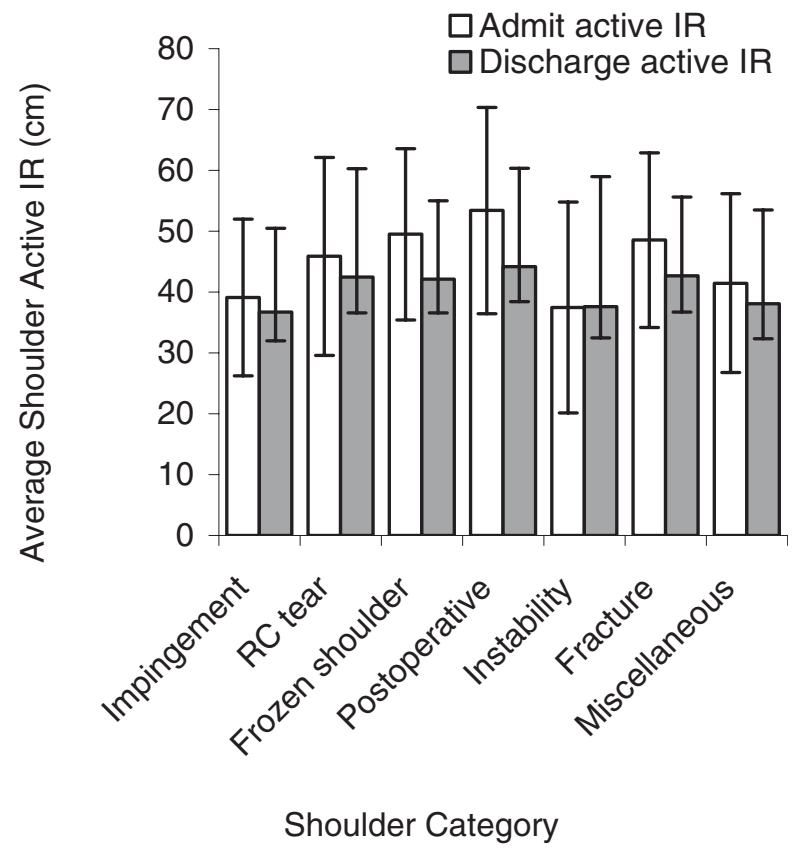

FIGURE 5. Admission and discharge shoulder active internal rotation range of motion (combined motion) by shoulder classification categories (bars represent mean $\pm \mathrm{SD}$ ).

them to a risk of rotator cuff tear significant enough to warrant surgery. Kronberg et $\mathrm{al}^{28}$ noted that of 40 consecutive clients who had shoulder surgery, 38 of the subjects were males, while only 2 were females. This ratio is even lower than that in our study.

The ages of our subjects (mean $\pm \mathrm{SD}, 52 \pm 16$ years) also appear to be comparable to those in the van der Windt et al study, ${ }^{35}$ although a direct comparison is not possible due to its use of age

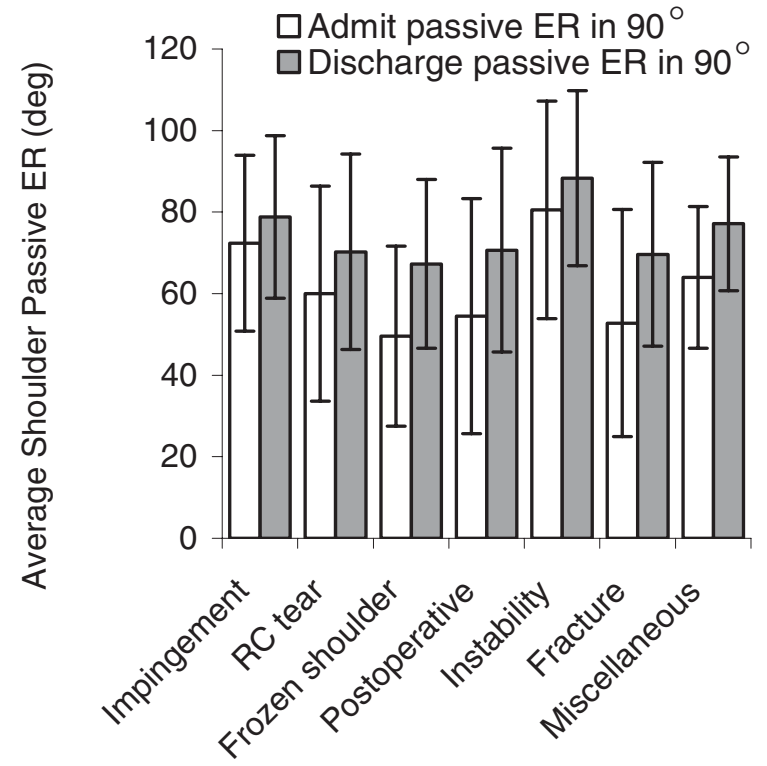

Shoulder Category

FIGURE 6. Admission and discharge shoulder passive external rotation (ER) motion in $90^{\circ}$ of abduction by shoulder classification categories (bars represent mean $\pm \mathrm{SD}$ ).

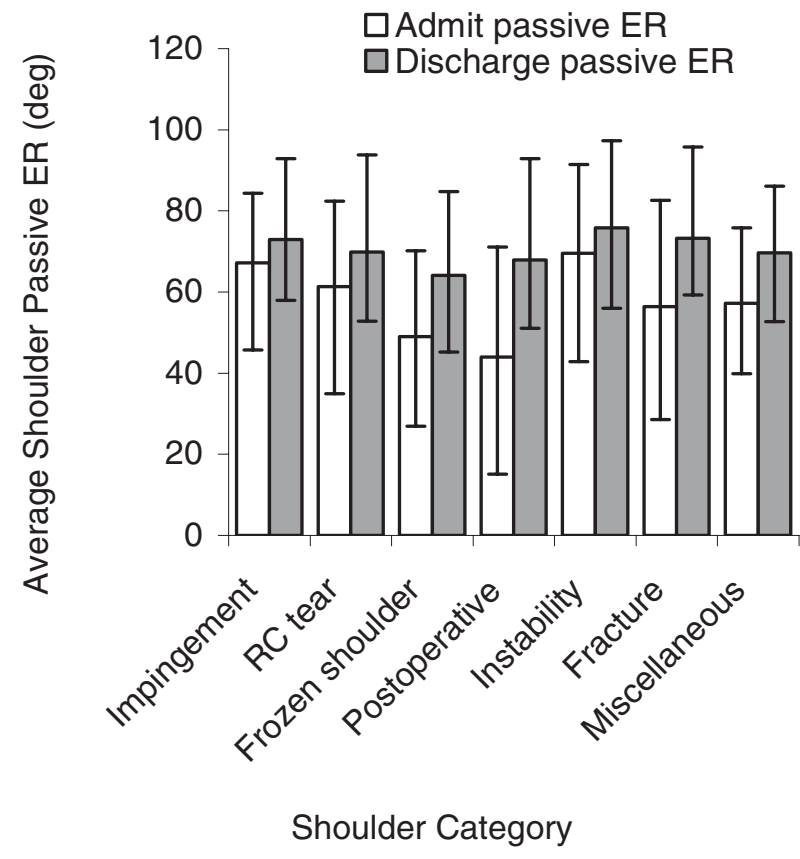

FIGURE 7. Admission and discharge shoulder passive external rotation (ER) motion in neutral abduction by shoulder classification categories (bars represent mean $\pm \mathrm{SD}$ ).

categories. They showed the largest number of subjects in the 45- to 64-year category. Ginn and colleagues ${ }^{19}$ reported averages of 62.7 and 56.4 years for the subjects in their study, which included numerous shoulder pathologies. Interestingly, the INS group was significantly younger, with an average age of $31 \pm 20$ years. This is slightly higher than the mean of 24 years noted by Warner et al. ${ }^{38}$ Our IMP group was also much older than that reported by Warner et $\mathrm{al}^{38}$ 


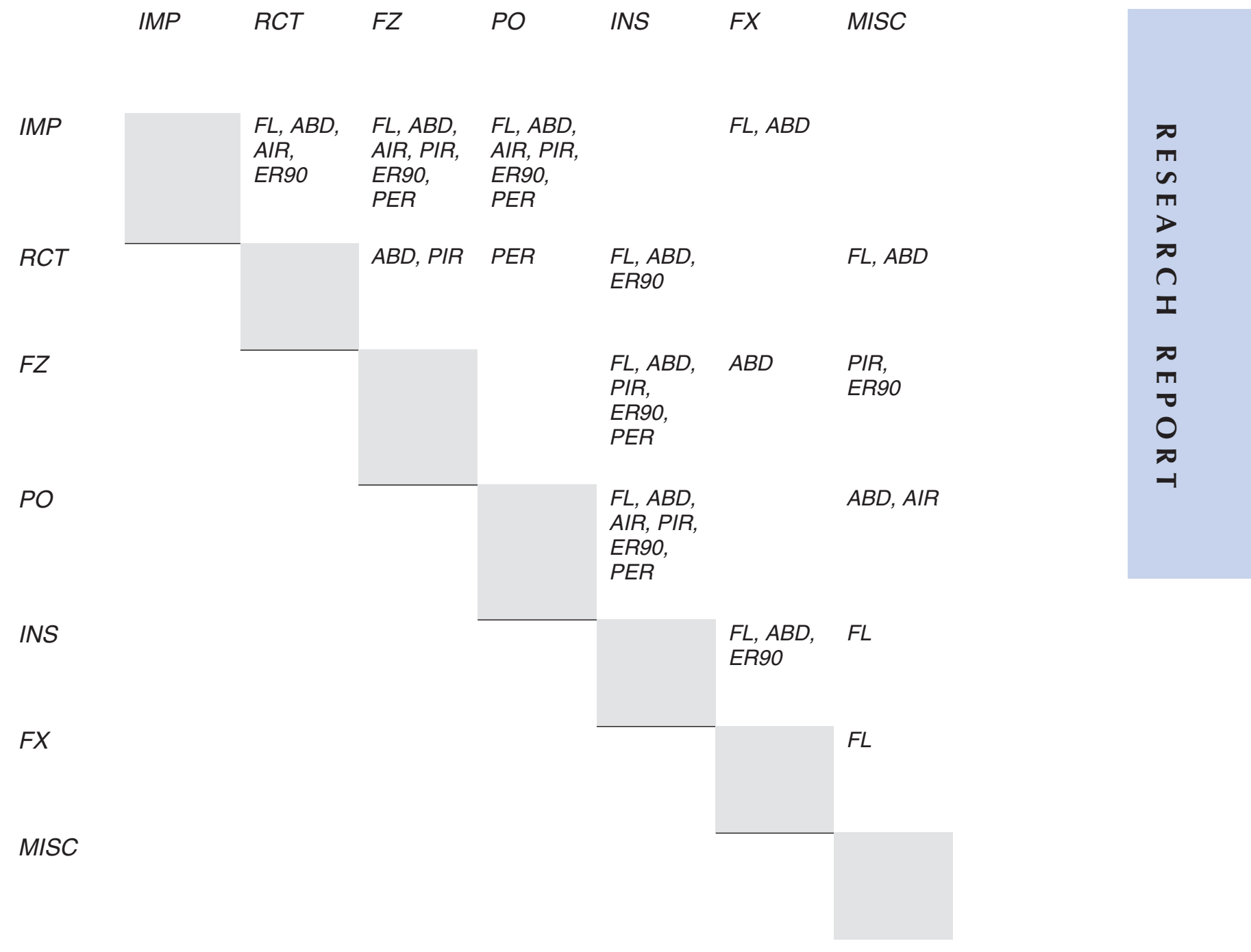

FIGURE 8. Summary of post hoc analyses from the repeated-measures ANOVAs for range-of-motion measures. ROM indicated in a block indicates that those 2 groups had significantly different responses based on post hoc testing $(P<.05)$. For example, the cell at the interception of RCT and FZ shows that these 2 groups had a different response for ABD (abduction) and PIR (passive internal rotation). Abbreviations: ABD, abduction; AIR, active internal rotation; ER90, passive external rotation in $90^{\circ}$ abduction; $F L$, flexion; $F X$, fracture; $F Z$, frozen shoulder; IMP, impingement; INS, instability; MISC, miscellaneous; PER, passive external rotation; PIR, passive internal rotation; PO, postoperative; RCT, rotator cuff tear.

(52 versus 31 years, respectively). However, their sample was a smaller, nonrandom sample.

The difference in the number of visits by each group was as expected. The clients who had surgery, along with those with a fracture or frozen shoulder, had the greatest impairments and disabilities at admission. In addition, there are usually restrictions placed upon therapy during the first 6 weeks to allow for healing of the surgical site. Either of these factors may translate into a longer treatment period with a greater number of visits, depending upon when the client was referred to physical therapy. These values fit within the number of visits identified by the Guide to Physical Therapist Practice. ${ }^{2}$

Within this study, approximately $40 \%$ of the clients reported having at least 1 comorbidity. These values are greater than those reported by van der Windt and colleagues, ${ }^{35}$ with only $12 \%$ of their clients with shoulder disorders having a comorbidity. However,
TABLE 7. Manual muscle test values (mean \pm SD [n]) for shoulder external rotation by shoulder classification. Strength is tested on a 0 -to- 5 scale, with 5 being normal.

\begin{tabular}{lcl}
\hline \multicolumn{1}{c}{ Shoulder Groups } & Admission Strength & Discharge Strength \\
\hline Impingement & $3.9 \pm 0.7(433)$ & $4.3 \pm .6(414)$ \\
Rotator cuff tear & $3.6 \pm 0.7(48)$ & $3.9 \pm 0.9(46)$ \\
Frozen shoulder & $3.8 \pm 0.7(72)$ & $4.1 \pm 0.7(66)$ \\
Postoperative & $3.6 \pm 0.8(97)$ & $4.2 \pm 0.7(98)$ \\
Instability & $3.9 \pm 0.7(25)$ & $4.3 \pm 0.5(25)$ \\
Fracture & $3.1 \pm 0.9(14)$ & $3.9 \pm 0.8(13)$ \\
Miscellaneous & $3.9 \pm 0.7(35)$ & $4.2 \pm 0.6(33)$ \\
Total & $3.8 \pm 0.7(724)$ & $4.2 \pm 0.6(695)$ \\
\hline
\end{tabular}

the number of comorbidities are more similar to those found by Boissonnault ${ }^{4}$ in a survey of clientsseeking outpatient physical therapy services in the United States. We believe this information emphasizes the importance of screening for systemic disease. 
One limitation to this study is that it only included those who sought physical therapy. In their study on shoulder problems in the elderly, Chard et $\mathrm{al}^{10}$ noted that only $40 \%$ of those tested had previously reported the problem to their physician. In addition, these individuals only represent 1 geographic region, which limits generalizability.

\section{Functional Tests}

The distribution within work status showed good changes, especially for the PO, FX, RCT, and MISC groups. Upon admission to physical therapy, more than half of the patients in each of these groups were within the off-work and restricted-duties categories. Following intervention, each of these groups had less than $30 \%$ of patients remaining in those 2 categories. Similarly, function showed a strong improvement, especially for the groups who started with a lower level of function (PO, FX, and RCT). Direct comparisons with other studies are limited by the use of different functional assessment forms, but the percentage change in our study averaged $21 \%$, which seems comparable to improvements reported in some intervention studies. Bang and Deyle ${ }^{3}$ used a 40-point functional scale in their study of clients with shoulder impingement. They showed improvements of $17 \%$ and $35 \%$ for the 2 intervention groups. Similarly, Ginn et $\mathrm{al}^{19}$ showed significantly better self-reported function for those that received physical therapy intervention versus a control group. In a study by Roach and colleagues, ${ }^{33}$ both function and ROM was shown to improve, with an inverse relationship between their functional scores and ROM, similar to our findings. Morrison et $\mathrm{al}^{29}$ found that $67 \%$ of those receiving physical therapy for subacromial impingement had improved function and movement. In a more recent study by Ginn and Cohen, ${ }^{17}$ function was found to improve by $88 \%$ at 6 months following conservative physical therapy interventions. However, postintervention measures were taken 6 months following treatment, thus there was an even greater chance that the changes could have been influenced by external variables. However, some studies that included individuals with chronic shoulder pain demonstrated significant improvements in function but no differences between types of treatment or groups. ${ }^{15,18,22}$

\section{Clinical tests}

The admission and discharge impairment measures were as anticipated. Shoulder ROM and strength were low upon initial assessment, and all showed noticeable changes following physical therapy interventions. The greatest magnitude of change for ROM was for shoulder flexion and abduction, followed by passive external rotation in $90^{\circ}$ abduction. Interpreta- tion of some admission measures are limited, especially for ROM or strength, as it may not have been appropriate to test individuals within each category (eg, PO group). This is similar to the results of Ginn and Cohen, ${ }^{17}$ who showed the greatest change for shoulder abduction ROM, followed by flexion. Hayes et $\mathrm{al}^{22}$ also found the greatest improvements in flexion and abduction for clients who had therapy following rotator cuff repair. Godges et $\mathrm{al}^{20}$ found an average improvement of $16^{\circ}$ in shoulder external rotation following intervention; however, they measured ER in $45^{\circ}$ of abduction. In addition, several studies have shown that healthy older individuals have less shoulder ROM as compared to that reported in previously published normative data. ${ }^{9,37} \mathrm{We}$ believe that the discharge shoulder motion values must be examined in relation to the ages of the clients. In examining the average amount of change in ROM, it is important to note the initial ROM for each individual. The wide variability (represented by the standard deviation) for the average improvement reflects the diversity of changes represented by each individual. For example, the average change noted for passive shoulder external rotation was $9.8^{\circ}$, with a large variation indicated by a standard deviation of $18.8^{\circ}$. Those with near-normal ROM would not exhibit large changes, while those with significant deficits had much greater changes. In one of the few studies that included a variety of shoulder dysfunctions, Ginn and colleagues ${ }^{19}$ used general interventions, including stretching, strengthening, and movement education. They showed improvements in ROM of $16^{\circ}$ for shoulder flexion (95\% CI, 0.6-30.5) and $22^{\circ}$ for abduction (95\% CI, 6.7-49.4). This compares well with the average increases shown in our study of $24^{\circ}$ and $25^{\circ}$, respectively. Their study also used a combined movement behind the back; but they recorded the vertebral level reached. For this motion, they showed no difference between the treatment group and the control group. We showed significant changes in this motion, perhaps due to the method of quantifying this measure, as well as a much larger sample size.

As noted, shoulder strength changed significantly, with an average increase of one half MMT grade. Interestingly, Hayes et $\mathrm{al}^{22}$ did not report the same amount of variation in their study, identifying a MMT range of 4.5 to 5.0 for their subjects at 6 weeks following rotator cuff repair, as compared to a range of 2.5 to 5.0 for our postsurgical group. Both groups in the Hayes et $\mathrm{al}^{22}$ study started active assisted shoulder motions at 8 days postoperatively, as well as isometric shoulder exercises for all directions. Perhaps differences in findings are a result of when active motions were initiated. Our findings of improved shoulder strength are as expected, based on the evidence provided by other studies which have used exercise as an intervention. 
One obvious limitation of this study is its retrospective, descriptive nature. Although assessment techniques were established prior to the implementation of the database, the primary purpose was for clinical consistency. The more rigid controls of a prospective design and focused study would have decreased some of the problems that were encountered. For example, we found problems due to multiple individuals, some who had not been properly trained, inputting data. This resulted in some data being eliminated. Related to the retrospective nature of the data is that some of the measures, such as the functional index, had limited validity and information regarding sensitivity. In addition, there is the possibility that some of the patients were misclassified for shoulder dysfunction. The sensitivity and specificity of many of the more common clinical diagnostic tests is limited. A limitation in analysis of these results is the use of admission values for discharge for those that stopped prior to the fifth visit, without a normal discharge. In these instances, no change would be reflected in the data, when in actuality there may have been changes in any or all values. Examination of the database showed that this was only the case for 35 clients (4\% of the total). It is unlikely that such a small portion of the sample would change the overall results, though if they did, it would probably result in less change being recorded than actually occurred.

\section{CONCLUSION}

Our study describes a sample of individuals who presented with shoulder dysfunction. Our use of a shoulder classification system allowed us to compare the demographics within the different categories, as well as to describe the typical presenting impairments and function. Our results show reduced impairments and improved function for clients with a variety of shoulder dysfunctions following participation in physical therapy.

\section{REFERENCES}

1. American Academy of Orthopaedic Surgeons. The Clinical Measurement of Joint Motion. Rosemont, IL: American Academy of Orthopaedic Surgeons; 1994.

2. American Physical Therapy Association. Guide to Physical Therapist Practice. Second Edition. American Physical Therapy Association. Phys Ther. 2001;81:9-746.

3. Bang MD, Deyle GD. Comparison of supervised exercise with and without manual physical therapy for patients with shoulder impingement syndrome. J Orthop Sports Phys Ther. 2000;30:126-137.

4. Boissonnault WG. Prevalence of comorbid conditions, surgeries, and medication use in a physical therapy outpatient population: a multicentered study. J Orthop Sports Phys Ther. 1999;29:506-519; discussion 520525 .
5. Boone DC, Azen SP, Lin CM, Spence C, Baron C, Lee L. Reliability of goniometric measurements. Phys Ther. 1978;58:1355-1390.

6. Brox JI, Staff PH, Ljunggren AE, Brevik JI. Arthroscopic surgery compared with supervised exercises in patients with rotator cuff disease (stage II impingement syndrome). BMJ. 1993;307:899-903.

7. Buss DD, Lynch GP, Meyer CP, Huber SM, Freehill MQ. Nonoperative management for in-season athletes with anterior shoulder instability. Am J Sports Med. 2004;32:1430-1433.

8. Casonato O, Musarra F, Frosi G, Testa M. The role of therapeutic exercise in the conflicting and unstable shoulder. Phys Ther Rev. 2003;8:69-84.

9. Chakravarty K, Webley M. Shoulder joint movement and its relationship to disability in the elderly. J Rheumatol. 1993;20:1359-1361.

10. Chard MD, Hazleman R, Hazleman BL, King RH, Reiss BB. Shoulder disorders in the elderly: a community survey. Arthritis Rheum. 1991;34:766-769.

11. Clarkson HM, Gilewich GB. Musculoskeletal Assessment: Joint Range of Motion and Manual Muscle Strength. Baltimore, MD: Williams \& Wilkins; 1999.

12. Cohen J. Statistical Power Analysis for the Behavioural Sciences. Hillsdale, NJ: Erlbaum; 1988.

13. Cyriax J. Textbook of Orthopaedic Medicine. 8th ed. London, UK: Bailliere Tindall; 1982.

14. Gang B, Schneider K. The Validity of the Shoulder Function Index [thesis]. Andrews University, Berrien Springs, MI, 1997.

15. Geraets JJ, Goossens ME, de Groot IJ, et al. Effectiveness of a graded exercise therapy program for patients with chronic shoulder complaints. Aust J Physiother. 2005;51:87-94.

16. Gerber C, Ganz R. Clinical assessment of instability of the shoulder. With special reference to anterior and posterior drawer tests. J Bone Joint Surg Br. 1984;66:551-556.

17. Ginn KA, Cohen ML. Conservative treatment for shoulder pain: prognostic indicators of outcome. Arch Phys Med Rehabil. 2004;85:1231-1235.

18. Ginn KA, Cohen ML. Exercise therapy for shoulder pain aimed at restoring neuromuscular control: a randomized comparative clinical trial. J Rehabil Med. 2005;37:115-122.

19. Ginn KA, Herbert RD, Khouw W, Lee R. A randomized, controlled clinical trial of a treatment for shoulder pain. Phys Ther. 1997;77:802-809; discussion 810.

20. Godges JJ, Mattson-Bell M, Thorpe D, Shah D. The immediate effects of soft tissue mobilization with proprioceptive neuromuscular facilitation on glenohumeral external rotation and overhead reach. J Orthop Sports Phys Ther. 2003;33:713-718.

21. Green S, Buchbinder R, Hetrick S. Physiotherapy interventions for shoulder pain. Cochrane Database Syst Rev. 2003;CD004258.

22. Hayes K, Ginn KA, Walton JR, Szomor ZL, Murrell GA. A randomised clinical trial evaluating the efficacy of physiotherapy after rotator cuff repair. Aust J Physiother. 2004;50:77-83.

23. Hayes K, Walton JR, Szomor ZL, Murrell GA. Reliability of 3 methods for assessing shoulder strength. J Shoulder Elbow Surg. 2002;11:33-39.

24. Heald SL, Riddle DL, Lamb RL. The shoulder pain and disability index: the construct validity and responsiveness of a region-specific disability measure. Phys Ther. 1997;77:1079-1089.

25. Hill JA. Epidemiologic perspective on shoulder injuries. In: Jobe FW, ed. Clinics in Sports Medicine. Philadelphia, PA: W.B. Saunders Company; 1983:241-246. 
26. Kendall FP, McCreary EK, Provance PG. Muscles: Testing and Function. 4th ed. Baltimore, MD: Williams \& Wilkins; 1993.

27. Kozin F. Two unique shoulder disorders. Adhesive capsulitis and reflex sympathetic dystrophy syndrome. Postgrad Med. 1983;73:207-216.

28. Kronberg $M$, Wahlstrom $P$, Brostrom LA. Shoulder function after surgical repair of rotator cuff tears. J Shoulder Elbow Surg. 1997;6:125-130.

29. Morrison DS, Frogameni AD, Woodworth P. Nonoperative treatment of subacromial impingement syndrome. J Bone Joint Surg Am. 1997;79:732-737.

30. National Collaborating Centre for Acute Care. Preoperative Tests: The Use of Routine Preoperative Tests for Elective Surgery: Evidence, Methods and Guidance. Available at: http://www.guidelines.gov/summary/ summary.aspx?ss = ss15\&doc_id $=5068 \& n b r=3552$. Accessed June, 2005.

31. Neer CS, 2nd. Impingement lesions. Clin Orthop Relat Res. 1983;70-77.

32. Riddle DL, Rothstein JM, Lamb RL. Goniometric reliability in a clinical setting. Shoulder measurements.
Phys Ther. 1987:67:668-673.

33. Roach KE, Budiman-Mak E, Songsiridej N, Lertratanakul Y. Development of a shoulder pain and disability index. Arthritis Care Res. 1991;4:143-149.

34. van den Dolder PA, Roberts DL. A trial into the effectiveness of soft tissue massage in the treatment of shoulder pain. Aust J Physiother. 2003;49:183-188.

35. van der Windt DA, Koes BW, de Jong BA, Bouter LM. Shoulder disorders in general practice: incidence, patient characteristics, and management. Ann Rheum Dis. 1995:54:959-964

36. Wadsworth CT, Krishnan R, Sear M, Harrold J, Nielsen $\mathrm{DH}$. Intrarater reliability of manual muscle testing and hand-held dynametric muscle testing. Phys Ther. 1987;67:1342-1347.

37. Walker JM, Sue D, Miles-Elkousy N, Ford G, Trevelyan $\mathrm{H}$. Active mobility of the extremities in older subjects. Phys Ther. 1984;64:919-923.

38. Warner JJ, Micheli LJ, Arslanian LE, Kennedy J, Kennedy R. Patterns of flexibility, laxity, and strength in normal shoulders and shoulders with instability and impingement. Am J Sports Med. 1990;18:366-375. 